\title{
PENDIAGNOSA DAUN MANGGA DENGAN MODEL CONVOLUTIONAL NEURAL NETWORK
}

\author{
Tsabitah Ayu, Vizza Dwi, Agus Eko Minarno
}

Universitas Muhammadiyah Malang

tsabitahayu@webmail.umm.ac.id,vizzavitanti@webmail.umm.ac.id,aguseko@webmail.umm.ac.id

\begin{abstract}
Abstrak - Pertanian adalah salah satu sektor ekonomi terpenting di negara-negara Asia Tenggara. Saat ini, pembangunan ekonomi sangat bergantung pada pertanian. Seperti contohnya Mangga, Mangga juga merupakan bahan makanan yang dapat diolah menjadi berbagai jenis makanan yang lezat. Oleh karena banyaknya manfaat pada buah ini tak jarang masyarakat ingin menanam pohon mangga untuk dibudidayakan dengan tujuan komersil maupun pribadi. Salah satu masalah utama yang menurunkan kualitas dan kuantitas manufaktur pertanian adalah penyakit tanaman. Oleh karena itu bidang penelitian pertanian menarik para peneliti dan ilmuwan untuk memberikan teknik untuk mengidentifikasi penyakit tanaman dengan menggunakan pengolahan gambar dan visi computer menggunakan model Convolutional Neural Network (CNN). Pengklasifikasian ini bertujuan untuk mengklasifikasi jenis daun mangga yang sakit (terserang hama) dan sehat berdasarkan bentuk dan tekstur daunnya. Dataset yang kita peroleh dari Kaggle memiliki total sejumlah 435 gambar daun mangga yang dibagi antara training dan test dan dikelompok dalam 2 kategori yaitu diseased dan healthy dengan epoch 100 dan dibagi menjadi 412 data train serta 23 data validasi. Pada penelitian ini dihasilkan tingkat akurasi sebesar 0.96 yang dianggap cukup baik dalam pengklasifikasian data.
\end{abstract}

Kata Kunci - CNN, Penyakit Daun Mangga, Klasifikasi.

Abstract - Agriculture is one of the most important economic sectors in Southeast Asian countries. Today, economic development relies heavily on agriculture. For example, Mango is also a food ingredient that can be processed into various types of delicious food. Because of the many benefits on this fruit is not uncommon people want to plant mango trees to be cultivated for commercial and personal purposes. One of the main problems that degrade the quality and quantity of agricultural manufacturing is crop disease. Therefore, the field of agricultural research attracted researchers and scientists to provide techniques to identify plant diseases using image processing and computer vision using the Convolutional Neural Network (CNN) model. This classification aims to classify the type of mango leaves that are sick (stricken by pests) and healthy based on the shape and texture of the leaves. Datasets that we obtained from Kaggle has a total of 435 images of mango leaves divided between training and test and grouped in 2 categories namely diseased and healthy with epoch 100 . In this study, an accuracy rate of 0.96 was recorded quite well in classifying data.

Keywords - CNN, Mango Leaf Disease, Classification.

\section{PENDAHULUAN}

Pertanian adalah salah satu sektor ekonomi terpenting di negara-negara Asia Tenggara. Saat ini, pembangunan ekonomi sangat bergantung pada pertanian [1]. Seperti contohnya Mangga, Mangga merupakan tanaman dengan nama latin Mangifera Indica L. yang berasal dari Negara India dan termasuk keluarga Anacardiacea. Tanaman ini menyebar ke wilayah Asia tenggara termasuk Indonesia [2]. Buah manga memiliki gizi yang sangat tinggi karena banyak mengandung vitamin $\mathrm{A}$ dan $\mathrm{C}$ yang dapat membantu meningkatkan ketahanan tubuh seperti mengurangi gejala kerusakan mata dan flu. Manga juga merupakan bahan makanan yang dapat diolah menjadi berbagai jenis makanan yang lezat. Oleh karena banyaknya manfaat pada buah ini tak jarang masyarakat ingin menanam pohon mangga untuk dibudidayakan dengan tujuan komersil maupun pribadi.
Salah satu masalah utama yang menurunkan kualitas dan kuantitas manufaktur pertanian adalah penyakit tanaman. Akibatnya, ini membawa dampak besar pada kerugian ekonomi [3]. Penyakit tanaman umumnya disebabkan oleh faktor alam seperti serangga, mengubah cuaca, suhu, dll. mengarah pada fakta bahwa diagnosis dini memainkan peran penting dalam pengobatan dan mencegah penyebaran penyakit. Oleh karena itu, bidang penelitian pertanian menarik para peneliti dan ilmuwan untuk memberikan teknik untuk mengidentifikasi penyakit tanaman yang diarahkan pada peningkatan produktivitas dengan biaya keuntungan yang lebih rendah. Berkat pengembangan dalam pengolahan gambar dan visi komputer, banyak aplikasi telah digunakan secara luas di bidang pertanian. Hal ini dapat menguntungkan petani dalam mendeteksi dan mengklasifikasikan penyakit tanaman secara otomatis. Dalam beberapa 
tahun terakhir, banyak penelitian telah dilakukan untuk identifikasi penyakit tanaman.

Dataset daun mangga ini diambil di dataset kaggle yang berisi 435 gambar daun mangga berekstensi .JPG. Dataset yang diambil merupakan jenis daun mangga yang sakit dan daun mangga yang sehat, dari data tersebut dilakukan proses klasifikasi jenis daun mangga sakit dan sehat dapat dilakukan dengan cara terkomputerisasi dengan pemanfaatan teknologi komputer yaitu pengolahan citra. Penggunaan suatu metode dalam sistem ini dapat memberikan tingkat akurasi penentuan dalam proses klasifikasi. Tujuan penelitian ini adalah melakukan klasifikasi jenis daun mangga yang sakit (terserang hama) dan sehat berdasarkan bentuk dan tekstur daun menggunakan model Convolutional Neural Network. CNN memiliki kinerja yang luar biasa dibidang klasifikasi gambar, CNN secara otomatis mengekstrak fitur dengan menggunakan convolution layer dan pooling layer, kemudian menggunakan neural network untuk klasifikasi fitur[4]. Digunakan model CNN karena dari penelitian sebelumnya yaitu pendeteksi jenis mangga di India dikatakan bahwa model $\mathrm{CNN}$ dapat mengklasifikasikan di antara berbagai jenis buah mangga dengan kinerja yang sangat memuaskan [5]. Diharapkan penelitian ini dapat menghasilkan hasil yang akurat sesuai dengan pengklasifikasian daun mangga yang ada dan dapat berguna dimasa mendatang.

\section{METODE PENELITIAN}

Berdasarkan penelitian yang akan dilakukan, sangat penting dalam melakukan sebuah penelitian dengan referensi dari penelitian terdahulu. Tujuannya untuk mengetahui hubungan antara penelitian yang akan dilakukan dengan penelitian terdahulu, sehingga dengan menambahkan acuan tersebut dapat menghindari adanya duplikasi dalam penelitian yang akan dilakukan. Saat ini sangat banyak pengembangan sistem yang meneladani Computer Vision seperti face detection, image recognition maupun pengenalan pola tetentu. Pengembangan sistem ini menjadi sebuah fungsionalitas yang dapat mempermudah perkerjaan diberbagai bidang. Pengembangan dari deep learning ini sangat efektif dan akurat untuk digunakan untuk menyelesaikan permasalahan tersebut. Hal ini tidak lepas dengan adanya riset atau penelitian di bidang tersebut. Penelitian terdahulu mengenai deep learning menggunakan convolutional neural network sudah banyak dilakukan oleh para peneliti pada berbagai macam objek. Seperti halnya penelitian yang dilakukan oleh peneliti sebelumnya yang menggunakan CNN guna mengklasifikasi motif batik [6].Dari penelitian sebelumnya yaitu pendeteksi jenis mangga di India dikatakan bahwa model CNN dapat mengklasifikasikan di antara berbagai jenis buah mangga dengan kinerja yang sangat memuaskan yaitu nilai AUCROC sebesar 97,3\%[7].

\section{A. Convolutional Neural Network}

Convolutional Neural Network (CNN) adalah salah satu jenis neural network yang biasa digunakan pada data image. CNN bisa digunakan untuk mendeteksi dan mengenali object pada sebuah image. CNN memanfaatkan proses konvolusi dengan menggerakan sebuah kernel konvolusi (filter) berukuran tertentu ke sebuah gambar, komputer mendapatkan informasi representatif baru dari hasil perkalian bagian gambar tersebut dengan filter yang digunakan. $\mathrm{CNN}$ dapat dengan mudah mengklasifikasikan objek dengan minimal preprocessing berhasil dalam menganalisis gambar visual dan dapat dengan mudah memisahkan fitur yang diperlukan yang terdiri dari convolutional layer, pooling layer, activation layer dan fully connected layer. Convolution dan pooling layer digunakan untuk feature extraction, dan fully connected layer untuk klasifikasi. Dengan convolution dan pooling, CNN secara bertahap memetakan inputan gambar ke dalam fitur dengan dimensi yang lebih rendah, kemudian menghasilkan feature vector. Sebagai algoritma deep learning, CNN telah mengungguli banyak metode konvensional dalam hal akurasi klasifikasi[8].

\section{B. Convolutional Layer}

Convolutional Layer adalah tahap pada CNN, dalam tahap ini dilakukan operasi konvolusi pada output dari layer sebelumnya. Konvolusi merupakan istilah matematis untuk pengaplikasian sebuah fungsi pada output fungsi yang lain secara berulang. Operasi ini menerapkan fungsi output sebagai Feature Map pada input citra. Gambar input diperkecil ke ukuran yang lebih kecil menggunakan filter. Filter digeser selangkah demi selangkah mulai dari sisi kiri atas gambar. Pada setiap Langkah, nilai pada gambar dikalikan dengan nilai filter dan hasilnya dijumlahkan. Sebuah matriks baru dengan ukuran lebih kecil dibuat dari gambar input [9].

\section{Pooling Layer}

Pooling adalah pengurangan ukuran pada matriks dengan menggunakan operasi pooling [10]. Pooling Layer biasanya terletak setelah convolutional layer. Pada dasarnya pooling layer terdiri dari sebuah filter yang memiliki ukuran dan langkah tertentu yang akan bergeser pada seluruh area pada feature map. Bentuk lapisan pooling umumnya menggunakan filter dengan ukuran 2x2 yang kemudian diaplikasikan dengan langkah sebanyak dua dan beroperasi pada setiap irisan dari inputnya. Max Pooling Layer adalah Teknik max pooling yang dilakukan dengan menerapkan filter maks ke sub wilayah yang non overlapping dari fitur input[11]. Max pooling digunakan untuk mengurangi dimentionalitas fitur.

\section{Activation Function}

Activation Function adalah node yang diletakkan di akhir atau di antara Neural Networks supaya hasil yang 
dikeluarkan lebih akurat lagi[12]. Fungsi ini untuk menentukan keluaran deep learning, akurasi, dan efisiensi komputasi untuk melatih model yang dapat membantu dan menghancurkan neural network skala besar. Dalam neural network, data numerik yang disebut input, dimasukkan ke neuron di input layer. Setiap neuron memiliki bobot, dan mengalikan jumlah input dengan bobot yang akan menghasilkan output dari neuron tersebut yang ditransfer ke layer berikutnya. Neural network semakin banyak menggunakan activation function non-linier yang dapat membantu mempelajari data kompleks, menghitung dan mempelajari hampir semua fungsi yang mewakili pertanyaan, dan memberikan prediksi yang akurat. Activation Function juga membantu menormalkan output dari input apa pun dalam kisaran antara 1 hingga -1 . Fungsi aktivasi harus efisien dan harus mengurangi waktu komputasi karena Neural network terkadang dilatih pada jutaan titik data. Activation Function pada dasarnya memutuskan dalam Neural network mana pun bahwa input atau penerimaan informasi yang diberikan relevan atau tidak relevan. Mari kita ambil contoh untuk memahami lebih baik apa itu neuron dan bagaimana fungsi aktivasi membatasi nilai output hingga batas tertentu. [13]

\section{E. Fully-Conected Layer}

Fully-Conected Layer merupakan lapisan dimana setiap neuron yang telah diaktivasi dari lapisan sebelumnya terhubung pada semua neuron di lapisan selanjutnya. Nilai matriks yang diperoleh setelah proses convolution, pooling, dan activation dimasukkan kedalam fully connected layer sebagai pengenalan input dan kalsifikasi di layer ini. Pada dasarnya lapisan ini digunakan pada Multi-Layer Perceptron (MLP) yang bertujuan untuk melakukan transformasi pada dimensi data agar data tersebut dapat diklasifikasikan secara linear. Flattening layer digunakan untuk mengubah tiga dimensi gambar menjadi tunggal untuk menemukan nilai probabilistik dengan dua fully connected dense layer yang terhubung dan berisi fungsi aktivasi yang diusulkan untuk klasifikasi.

Penentuan baik tidaknya performa suatu model klasifikasi dapat dilihat dari pengukuran performa parameternya, yaitu tingkat akurasi, recall, dan presisi.

\section{F. Confusion Matriks}

Confusion matrix merupakan sebuah table yang terdiri dari banyaknya baris data uji yang diprediksi benar dan tidak benar oleh model klasifikasi. Tabel ini diperlukan untuk mengukur kinerja suatu model klasifikasi. Confusion matrix adalah alat yang berguna untuk menganalisis seberapa baik classifier/pengelompokan dapat mengenali tupel dari kelas yang berbeda. Dalam pembuatan table confusion matrix ada empat hal yang harus diketahui, yaitu:
TABEL I

CONFUSION MATRIKS

kejadian sebenarnya

\begin{tabular}{cc|c|c|}
\multicolumn{1}{c}{} & \multicolumn{1}{c}{$\mathrm{P}$} & \multicolumn{1}{c}{$\mathrm{N}$} \\
\cline { 3 - 4 } $\begin{array}{c}\text { hipotesis } \\
\text { kejadian }\end{array}$ & $\mathrm{P}$ & $\begin{array}{c}\text { true } \\
\text { positive }\end{array}$ & $\begin{array}{c}\text { false } \\
\text { positive }\end{array}$ \\
\cline { 3 - 4 } & $\mathrm{N}$ & $\begin{array}{c}\text { false } \\
\text { negative }\end{array}$ & $\begin{array}{c}\text { true } \\
\text { negative }\end{array}$ \\
\cline { 3 - 4 } & &
\end{tabular}

Recall digunakan sebagai pengukur fraksi pola positif yang akan diklasifikasi dengan benar, sedangkan fungsi precision adalah recall dari total pola prediksi pada kelas positif, F-Measure merupakan ukuran dari rata-rata yang seimbang antara recall dan precision, dan accuracy merupakan ratio prediksi benar terhadap keseluruhan sampel yang dievaluasi [14].

Berdasarkan tabel diatas terdapat beberapa nilai yang ada pada matriks yaitu "True Positive" (TP), "True Negative" (TN), "False Positive" (FP), dan "False Negative" (FN), seluruh kemungkinan kejadian sebenarnya positif (P) dan seluruh kemungkinan kejadian sebenarnya negatif $(\mathrm{N})$. Nilai tersebut nantinya dapat digunakan untuk menghitung akurasi dengan persamaan (1)

$$
\text { akurasi }=\frac{(T P+T N)}{P+N}
$$

Akurasi yang ada kemudian digunakan sebagai parameter sebagaimana akurat atau tidaknya suatu model dalam melakukan klasifikasi.

Sementara untuk menghitung tingkat presisi prediksi kejadian dapat digunakan persamaan (2)

$$
\text { presisi prediksi }=\frac{T P}{T P+F P}
$$

Dari hasil presisi diatas digunakan untuk menggambarkan seberapa tepat suatu model memprediksi kejadian positif dalam serangkaian kegiatan prediksi.

Selain presisi dan akurasi, untuk melihat lebih detail kinerja suatu sistem, recall atau sensitivitas sistem terhadap suatu kelas juga dapat dilihat. Recall dapat dihitung dengan menggunakan persamaan (3)

$$
\text { sensifitas prediksi }=\frac{T P}{T P+F P}
$$

\section{HASIL DAN PEMBAHASAN}

Dalam penelitian ini, metode CNN digunakan untuk mendeteksi penyakit/bakteri pada daun manga. CNN merupakan salah satu kategori utama pengenalan gambar dan klasifikasi gambar. CNN biasanya digunakan untuk mendeteksi dan mengidentifikasi objek sehingga kami memilih CNN untuk memecahkan masalah pada penelitian kami. Dataset yang kita peroleh dari Kaggle memiliki total sejumlah 435 gambar daun mangga yang dibagi antara training dan test dan dikelompok dalam 2 kategori yaitu diseased 
dan healthy yang ditunjukkan pada gbr 1(a) dan gbr $1(b)$.

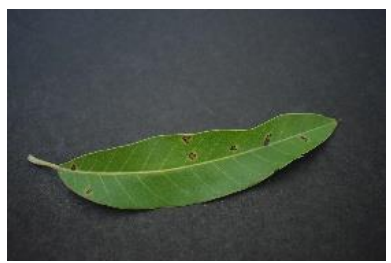

Gbr. 1(a) diseased mango leave

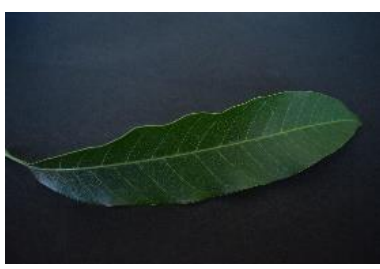

Gbr. 1(b) Healthy mango leave

Tahap pertama yang dilakukan adalah pengimporan library yang dibutuhkan untuk mengelola gambar dengan metode CNN, kemudian dilanjutkan dengan prepossessing dataset daun mangga yaitu dengan cara gathering data test, train dan validation. Terlihat pada dataset tersebut memiliki 412 data train dan 23 data validasi, dengan dimensi tiap imagenya 250 x 250, dan terdiri dari 3 channel (R, G, B).

Tahap selanjutnya yaitu penormalisasian data yang semula data berupa integer memiliki range 0-255 dengan nilai [ $\left.8 \begin{array}{lll}81 & 67 & 55\end{array}\right]$ dinormalisasi menjadi float dengan range 0-1 menjadi [0.31764707 0.2627451 0.21568 ]. Tahap penormalisasian selanjutnya yaitu merubah label class dari healthy dan diseased menjadi binary yakni 0 dan 1 .

Model: "sequential_2"

\begin{tabular}{|c|c|c|}
\hline 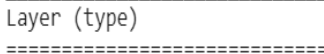 & $\begin{array}{l}\text { Output Shape } \\
====================:=\end{array}$ & Param \# \\
\hline conv2d_6 (Conv2D) & (None, 248, 248, 32) & 896 \\
\hline max_pooling2d_6 (MaxPooling2 & (None, 124, 124, 32) & 0 \\
\hline conv2d_7 (Conv2D) & (None, 122, 122, 64) & 18496 \\
\hline max_pooling2d_7 (MaxPooling2 & (None, 61, 61, 64) & 0 \\
\hline conv2d_8 (Conv2D) & (None, 59, 59, 128) & 73856 \\
\hline max_pooling2d_8 (MaxPooling2 & (None, 29, 29, 128) & 0 \\
\hline global_max_pooling2d_2 (Glob & (None, 128) & 0 \\
\hline flatten_2 (Flatten) & (None, 128) & 0 \\
\hline dense_14 (Dense) & (None, 512) & 66048 \\
\hline dense_15 (Dense) & (None, 256) & 131328 \\
\hline dense_16 (Dense) & (None, 128) & 32896 \\
\hline dense_17 (Dense) & (None, 64) & 8256 \\
\hline dense_18 (Dense) & (None, 32) & 2080 \\
\hline dense_19 (Dense) & (None, 16) & 528 \\
\hline dense_20 (Dense) & (None, 1) & 17 \\
\hline
\end{tabular}

Total params: 334,401

Trainable params: 334,401

Non-trainable params: $\theta$

Tahap selanjutnya merupakan training model dengan epoch 100. Untuk tahap evaluasi model, pada penelitian ini menampilkan grafik loss dan akurasi dari model CNN yang digunakan yang ditunjukkan pada gbr 3(a) dan gbr 3(b) di bawah ini.

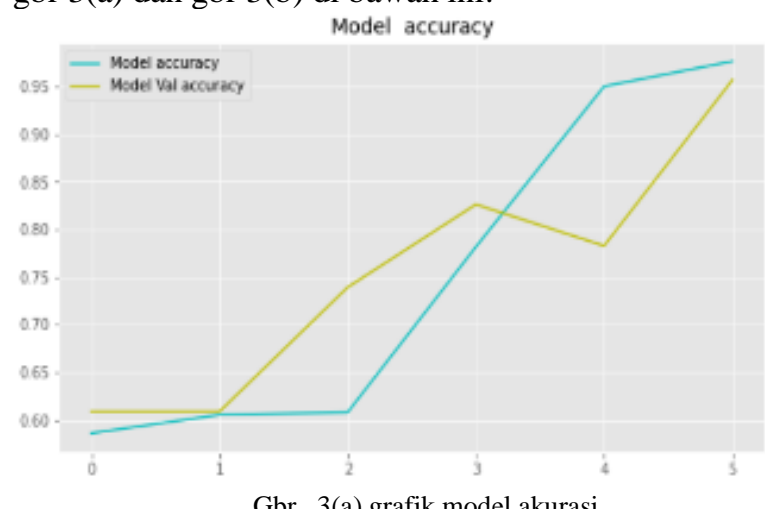

Gbr. 3(a) grafik model akurasi

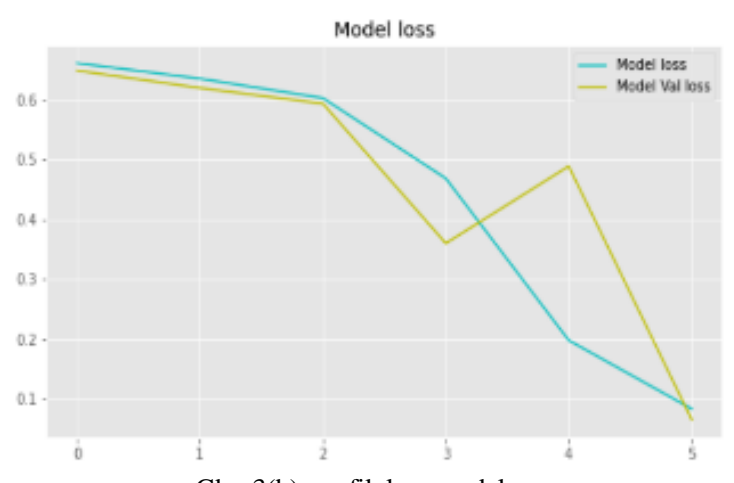

Gbr. 3(b) grafik loss model

Dari tahap yang telah dilakukan sebelumnya menghasilkan matriks classification report dengan akurasi sebesar 0.96 seperti yang terdapat pada gbr 4 yang menunjukkan bahwa model CNN yang digunakan dan dinilai cukup akurat untuk mendiagnosis daun mangga yang terserang hama dengan daun mangga yang sehat.

$\begin{array}{rrrrr} & \text { precision } & \text { recall } & \text { f1-score } & \text { support } \\ 0 & 1.00 & 0.93 & 0.96 & 14 \\ 1 & 0.90 & 1.00 & 0.95 & 9 \\ & & & & \\ \text { accuracy } & & & 0.96 & 23 \\ \text { macro avg } & 0.95 & 0.96 & 0.96 & 23 \\ \text { weighted avg } & 0.96 & 0.96 & 0.96 & 23\end{array}$

Gbr. 4 Classification report

Selanjutnya yaitu tahap uji coba dari model CNN yang digunakan yaitu berupa prediksi dengan menginputkan contoh daun mangga yang terinfeksi dan output yang diberikan sesuai dengan kondisi daun yang telah diinputkan hal ini dapat dilihat pada gbr 5(a) dan 5(b) dibawah ini.

Gbr. 2 summary model 


\section{Choone filias No file chosen Upload wid Saving $\theta 812 \_8001$.JPG to $8012 \_8001$ (1).JPG Prediksi - e.e \\ Prediksi Ganbar Tersebut adalah Diseased}

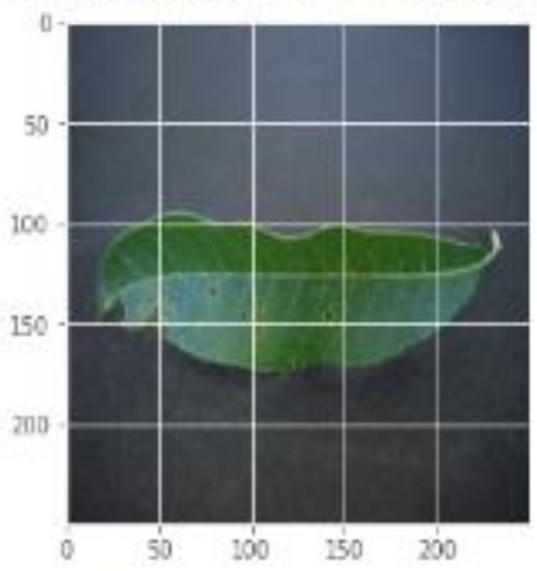

Gbr. 5(a) uji coba daun sakit

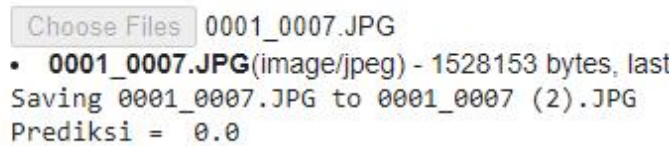

Prediksi Gambar adalah Daun Mangga Sehat

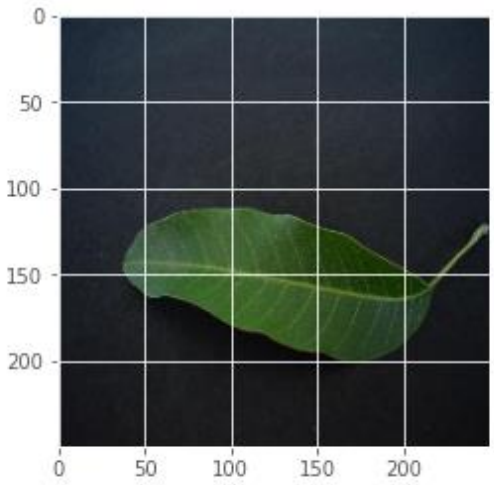

Gbr. 5(b) uji coba daun sehat

\section{KESIMPULAN}

Dalam pertanian mangga tentu memiliki beberapa kendala diantaranya adalah penyakit pada daun manga yang jika dibiarkan akan akan menghasilkan produk yang gagal panen. Dengan memanfaatkan teknologi berupa pendeteksi penyakit pada daun manga dengan menggunakan Model Convolutional Neural Network (CNN) maka hal ini bisa diatasi. Dari penjelasan sebelumnya dapat disimpulkan bahwa pada penelitian menggunakan Model Convolutional Neural Network (CNN) ini dapat membantu para petani untuk membedakan antara daun yang terserang hama dengan daun yang sehat. Dataset yang diambil berupa gambar sebanyak 435 gambar dari 32 jenis mangga dengan ekstensi .JPG. Dari hasil penelitian diatas didapatkan tingkat akurasi sebesar 0.96 yang berarti dinilai cukup akurat untuk mendiagnosis daun mangga yang terserang hama dengan daun mangga yang sehat. Diharapkan dengan adanya penelitian ini dapat bermanfaat bagi para petani mangga.

\section{UCAPAN TERIMA KASIH}

Dalam pembuatan paper ini banyak pihak yang membantu penulis sehingga dapat menyelesaikan paper ini, untuk itu Penulis mengucapkan terimakasih kepada:

1. Allah SWT atas limpahan karunia dan hidayahNya sehingga dapat menyelesaikan pembuatan paper.

2. Bapak Agus Eko Minarno selaku dosen pembimbing atas bimbingan, arahan dan koreksinya selama penyusunan dan penulisan paper.

3. Kedua orangtua yang telah membantu dan mendukung dalam mengerjakan paper ini

4. Teman teman yang mendukung dalam penyusunan dan penulisan paper

5. Reviewer CESS (Journal of Computer Engineering, System and Science)

\section{REFERENSI}

[1] K. Trang, L. Tonthat, N. Gia Minh Thao, and N. Tran Ta Thi, "Mango Diseases Identification by a Deep Residual Network with Contrast Enhancement and Transfer Learning," 2019 IEEE Conf. Sustain. Util. Dev. Eng. Technol. CSUDET 2019, pp. 138-142, 2019, doi: 10.1109/CSUDET47057.2019.9214620.

[2] Mekarsari, "Mangga," mekarsari.com.

[3] Z. Iqbal, M. A. Khan, M. Sharif, J. H. Shah, M. H. ur Rehman, and K. Javed, "An automated detection and classification of citrus plant diseases using image processing techniques: A review," Comput. Electron. Agric., vol. 153, no. September 2017, pp. 12-32, 2018, doi: 10.1016/j.compag.2018.07.032.

[4] Y. Zhang, Q. Hua, D. Xu, H. Li, Y. Bu, and P. Zhao, "A Complex-Valued CNN for Different Activation Functions in Polarsar Image Classification," Int. Geosci. Remote Sens. Symp., pp. 10023-10026, 2019, doi: 10.1109/IGARSS.2019.8898534.

[5] S. Islam and N. Jahan, "A Computer Vision Approach to Classify Local Flower using Convolutional Neural Network," no. May, 2020, doi: 10.1109/ICICCS48265.2020.9121143.

[6] A. Y. Wicaksono, N. Suciati, C. Fatichah, K. Uchimura, and G. Koutaki, "Modified Convolutional Neural Network Architecture for Batik Motif Image Classification," IPTEK J. Sci., vol. 2, no. 2, pp. 26-30, 2017, doi: 10.12962/j23378530.v2i2.a2846.

[7] A. S. M. F. Al Haque, M. R. Rahman, A. Al Marouf, and M. A. A. Khan, "A Computer Vision System for Bangladeshi Local Mango Breed Detection using Convolutional Neural Network (CNN) Models," 2019 4th Int. Conf. Electr. Inf. Commun. Technol. EICT 2019, no. December, pp. 1-6, 2019, doi: 10.1109/EICT48899.2019.9068830.

[8] S. Lu, Z. Lu, S. Aok, and L. Graham, "Fruit Classification Based on Six Layer Convolutional Neural Network," Int. Conf. Digit. Signal Process. DSP, vol. 2018-Novem, pp. 1-5, 2019, doi: 10.1109/ICDSP.2018.8631562.

[9] M. Sardogan, A. Tuncer, and Y. Ozen, "Plant Leaf Disease Detection and Classification Based on CNN with LVQ Algorithm," UBMK 2018 - 3rd Int. Conf. Comput. Sci. Eng., pp. 382-385, 2018, doi: 10.1109/UBMK.2018.8566635.

[10] C. K. Dewa, A. L. Fadhilah, and A. Afiahayati, "Convolutional Neural Networks for Handwritten Javanese Character Recognition," IJCCS (Indonesian J. Comput. Cybern. Syst., vol. 12, no. 1, p. 83, 2018, doi: 10.22146/ijccs.31144. 
[11] D. Ciregan, U. Meier, and J. Schmidhuber, "Multi-column deep neural networks for image classification," Proc. IEEE Comput. Soc. Conf. Comput. Vis. Pattern Recognit., pp. 36423649, 2012, doi: 10.1109/CVPR.2012.6248110

[12] C. K. Dewa and Afiahayati, "Suitable CNN Weight Initialization and Activation Function for Javanese Vowels

Page | 235 Classification," Procedia Comput. Sci., vol. 144, pp. 124-132, 2018, doi: 10.1016/j.procs.2018.10.512.

[13] Dinesh Kumawat, "No Title," 2021. https://www.analyticssteps.com/blogs/7-types-activationfunctions-neural-network (accessed Jul. 22, 2021).

[14] A. S. Sri Widaningsih, "Klasifikasi Jurnal Ilmu Komputer Berdasarkan Pembagian," Semin. Nas. Teknol. Inf. dan Komun. 2018 (SENTIKA 2018), vol. 2018, no. Sentika, pp. $320-328,2018$. 